\title{
An Empirical Test of Formal Equivalence between Emmert's Law and the Size-Distance Invariance Hypothesis
}

\author{
Mariko Imamura and Sachio Nakamizo \\ Kyushu University, Japan
}

\begin{abstract}
Emmert's law and the size-distance invariance hypothesis have been said to be formally equivalent, provided that Emmert's law means that the perceived size of an afterimage is proportional to the perceived distance of the projected surface of the afterimage. However, there have been very few studies that have attempted to verify this formal equivalence empirically. We measured both the perceived size and distance of afterimages and real objects with the same proximal size. Nineteen participants projected afterimages of 1 deg in visual angle on the wall located at distances of 1 to 23 meters from the participants. They also observed real objects, disc-shaped and made from a sheet of Styrofoam board, with the same proximal size as that of the afterimages, which were located at the same physical distances as those of the wall on which the afterimages were projected. Each participant reproduced the apparent sizes of the afterimages and real objects using the reproduction method and estimated the apparent distances using the magnitude estimation method. When the mean apparent sizes of the afterimages and real objects, represented as a function of apparent distance, were fitted to a linear function, the slopes for the afterimages and real objects did not differ significantly. These results are interpreted as evidence for the formal equivalence of Emmert's law and the size-distance invariance hypothesis.

Keywords: Emmert's law, size-distance invariance hypothesis, afterimage, size perception, distance perception
\end{abstract}

Es común considerar a la ley de Emmert y la hipótesis de la invarianza del tamaño-distancia como equivalentes formalmente. Para llegar a esta conclusión se parte de considerar que, al aplicar la ley de Emmert, el tamaño percibido de la postimagen es proporcional a la distancia percibida de la superficie en la que se proyecta. A pesar de lo anterior, muy pocos estudios han intentado verificar empíricamente esta equivalencia formal. En este trabajo se midió tanto el tamaño percibido como la distancia de postimágenes y de objetos reales con el mismo tamaño proximal. 19 participantes proyectaron postimágenes con un ángulo visual de 1 grado sobre una pared de 1 a 23 metros respecto a los participantes. Estos también observaron objetos reales, en forma de discos, hechos de una plancha de espuma Styrofoam, con el mismo tamaño proximal que el de las postimágenes, que se colocaron a las mismas distancias físicas que las de la pared sobre la que se proyectaron las postimágenes. Cada participante reprodujo los tamaños aparentes de las postimágenes y de los objetos reales usando el método de reproducción y estimó las distancias aparentes empleando el método de estimación de magnitudes. Cuando los tamaños medios aparentes de las postimágenes y de los objetos reales, representados en función de la distancia aparente, se ajustaron a una función lineal, las pendientes de las postimágenes y de los objetos reales no diferían significativamente. Estos resultados se interpretan como evidencia para la equivalencia formal de la ley de Emmert y la hipótesis de la invarianza del tamaño-distancia. Palabras clave: Ley de Emmert, hipótesis de la invarianza tamaño-distancia, postimagen, percepción del tamaño, percepción de la distancia

This research was supported by a Grant-in-aid for Scientific Research (Houga kenkyu 17653089) and by the COE program provided by the Japanese Ministry of Education, Science, and Culture to the second author. The authors wish to thank staff members of the vision group of the Department of Psychology, Kyushu University for their helpful comments and discussions on earlier versions of this paper. This paper was published in VISION, the journal of the Japanese Vision Society, written in Japanese.

Correspondence concerning this article should be sent to Sachio Nakamizo. Department of psychology, Faculty of Human-Environment Studies, Kyushu University, 9-19-1, Hakozaki, Higashik, Fukuoka, Japan. Tel \& Fax: +81-92-642-2416.

E-mail: nakamizo@ lit.kyushu-u.ac.jp 
Two different interpretations of Emmert's law have been proposed. One is that the "physical size" of an afterimage ${ }^{1}$ is proportional to the "physical distance" of a surface on which the afterimage is projected. We call this the physical sizedistance interpretation of Emmert's law. Another interpretation is that the "perceived size" of the afterimage is proportional to the "perceived distance" of the surface. We call this the apparent size-distance interpretation of Emmert's law.

The physical size-distance interpretation states that the physical size of the afterimage, that is, the physical size of the area on the projected surface that the afterimage occupies, proportionally increases (or decreases) as the physical distance of the projected surface increases (or decreases). Emmert's law, under this interpretation, can be represented by the following equation:

$$
S=D \cdot \tan \theta
$$

where $S$ is the physical size, $D$ is the physical distance, and $\theta$ is the angle subtended by the afterimage. As all the variables in Equation 1 can be physically defined, Emmert's law can be said to be a geometric law, not psychophysical one. The validity of this physical interpretation of Emmert's law has been demonstrated by Weintraub and Gardner (1970) and Young (1948).

The apparent size-distance interpretation states that the apparent size of the afterimage on the projected surface proportionally increases (or decreases) as the apparent distance of the projected surface increases (or decreases). Emmert's law, under this interpretation, can be represented by the following equation:

$$
s=d \cdot \tan \theta
$$

where $s$ is the apparent size of the afterimage, $d$ is the apparent distance of the projected surface, and $\theta$ is the visual angle subtended by the afterimage. The physical variables $(S, D)$ in Equation 1 are replaced by the psychophysical variables $(s, d)$ in Equation 2 . The validity of Equation 2 has been demonstrated by Inoue (1972) and Nakamizo and Imamura (2004), who found that the perceived size of the afterimage is proportional to the perceived distance of the projected surface, and the slope of the linear function fitted to the mean perceived size and distance is very close to the slope of Equation 2 in which appropriate numerical variables are substituted. The present study adopted Equation 2 as a formal statement of Emmert's law.

There have been arguments that Emmert's law, which is represented by Equation 2, is formally equivalent to the size-distance invariance hypothesis (e.g., Higashiyama, 1994; Howard \& Rogers, 2002). For instance, Howard and Rogers (2002) stated that if Emmert's law is interpreted to mean that the perceived size of an afterimage is proportional to its perceived distance, it is a statement about a perceptual mechanism and is equivalent to the size-distance invariance hypothesis. The only difference is that Emmert's law gives a relationship between the perceived size of an afterimage and the perceived distance of a projected surface, whereas the size-distance invariance hypothesis gives a relationship between the perceived size and distance of an actual object.

The formal equivalence can be shown as follows. The size-distance invariance hypothesis means that for an image of a given perceived size, the perceived object size is proportional to the perceived distance and the ratio of the perceived object size to the perceived distance is constant (Howard \& Rogers, 2002). The hypothesis can be represented by the following equation:

$$
\frac{\mathrm{s}}{\mathrm{d}}=K(\mathrm{~K} \text { is constant })
$$

where $s$ is the perceived object size, and $d$ is the perceived distance. Equation 3 can be transformed into the following equation:

$$
s=d \cdot K
$$

Equation 2 and Equation 4 are formally equivalent because $\tan \theta$ is constant for the visual angle subtended by the afterimage.

As far as we have surveyed references, there has been no empirical study at all to test this formal equivalency of Emmert's law and the size-distance invariance hypothesis using equivalent methods and experimental environments. The aim of the present study was to test this formal equivalency by using an afterimage and real objects with the same proximal sizes and with the same viewing distances in the same environment.

\section{Method}

\section{Participants}

Nineteen volunteers (10 female and 9 male university students) participated in the experiment. All observers were naïve as to the purpose of the experiment. Written consent was obtained from all observers. All had normal or correctedto-normal visual acuity.

\section{Stimulus and Apparatus}

Two stimuli were used: One was an afterimage and the other was a disc-shaped real object. A positive afterimage with a constant visual angle $\left(1^{\circ}\right)$ was induced by flashing

\footnotetext{
1 Here, the physical size of an afterimage means the physical size of the area on the projected surface that the afterimage occupies.
} 
into the observers' eyes with an electric photoflash (National NE-5651), masked to provide a disc-shaped afterimage. There was a fixation mark at the center of the window of the mask. The disc-shaped real objects were made from a sheet of Styrofoam board, $7 \mathrm{~mm}$ thick. The proximal size of the real objects was always $1^{\circ}$ in visual angle in all viewing distance conditions and their physical sizes were 1.8, 5.2, 10, 15, 20, 24,32 , and $40 \mathrm{~cm}$ corresponding to the viewing distances.

\section{Procedure}

The experiment was conducted in a corridor in a university building, which was $2.06 \mathrm{~m}$ wide, $3.02 \mathrm{~m}$ high, and $26.83 \mathrm{~m}$ long. The corridor was illuminated by fluorescent lamps from the ceiling of the corridor. The windows on the two long sides of the corridor and the texture of its floor served as perspective cues to distance; therefore, the experimental environment was a full-cue viewing condition. A white wall at one end of the corridor was the surface upon which the afterimage was projected. The luminance of the surface was $250 \mathrm{~cd} / \mathrm{m}^{2}$.

The magnitude estimation method was used to measure the perceived distance of the surface and a matching method was used to measure the perceived sizes of the afterimage and the real objects. The observer was required to perform three tasks. The first was to report the apparent distance of the surface by reporting a number with a modulus as a unit, which was a 1-m long stick, so that the number corresponded to the perceived distance of the surface. The second task was to match the apparent size of the afterimage with a length of tape that the observer held in the hand. The third task was to match the apparent size of the real object with the same method as that for the afterimage. Each of the three tasks was performed in different sessions to ensure that each task did not affect the results of the other tasks. The participant performed each task in an upright posture. Eight viewing distances 1, 3, 5.7, 11.5, 13.8, 18.3, and $23.0 \mathrm{~m}$ were employed. The order of the tasks was randomized for the participants. Each participant performed three 8-trial sessions for each task. In each session, eight viewing distances were included in random order. After the photoflash was exposed to the observer for the afterimage task, it was removed from the observer's line of sight. The observer projected an afterimage on the wall of the corridor.

\section{Results}

\section{Perceived Size}

The mean perceived sizes of each stimulus averaged over three trials for each participant and for each viewing distance were the basic unit for further analyses. A two-way (2 Types of Stimulus $\times 8$ Viewing Distances) repeated measures ANOVA was performed. The results showed that the main effects of the type of stimulus and the viewing distance were significant: stimulus type, $F(2,18)=9.672, p<.01$; viewing distance, $F(7,126)=222.012, p<.001$. The results of multiple comparisons (Ryan's method) showed significant differences in the mean perceived size between the afterimage and real object in the viewing distance conditions of 13.8 , 18.3, and $22.9 \mathrm{~m}$. Figure 1 shows the mean perceived size averaged over 19 participants plotted as a function of the viewing distance, separately for each type of stimulus.

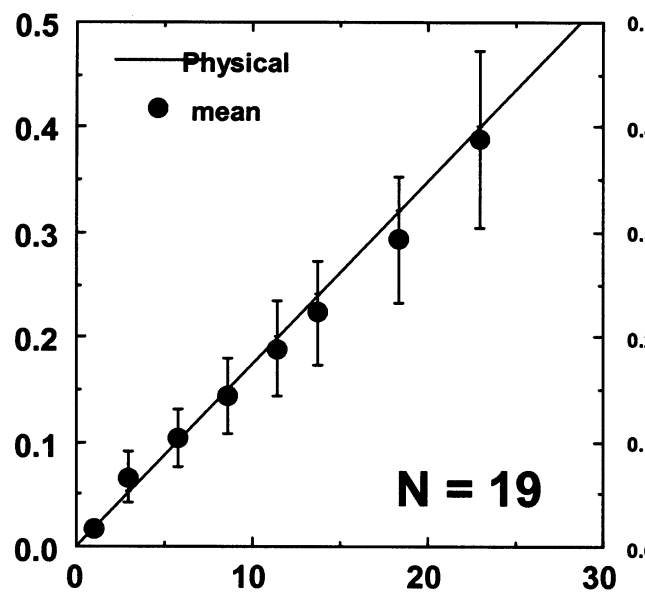

Viewing Distance (m)

(a)

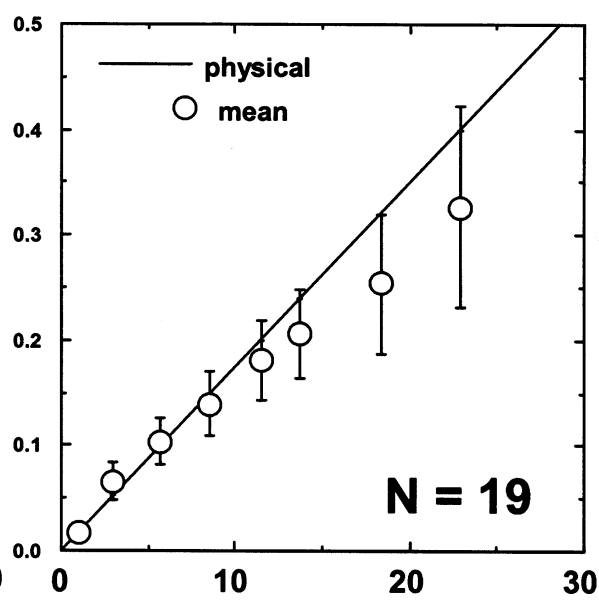

Viewing Distance $(\mathrm{m})$

(b)

Figure 1. The mean perceived size plotted as a function of viewing distance. (a) real object and (b) afterimage. The thin vertical lines indicate the standard deviations. 


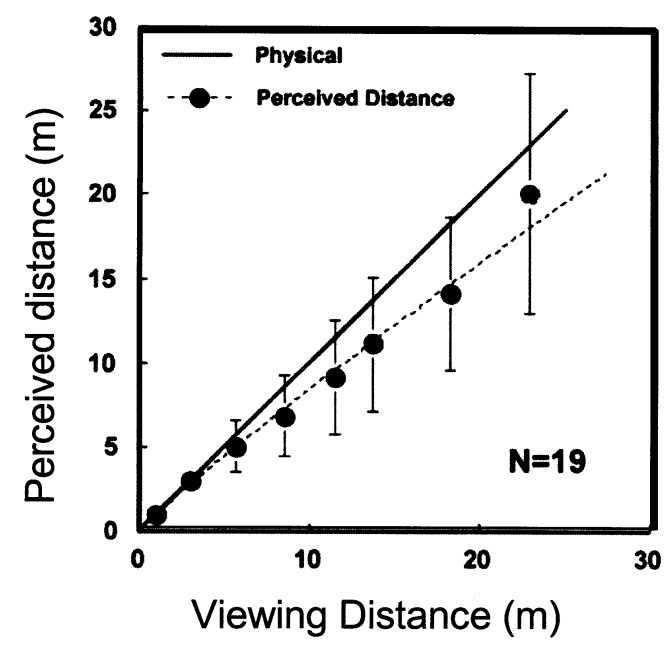

Figure 2. The mean perceived distance plotted as a function of the viewing distance. The solid line indicates the physical distance and the dotted line indicates the power function fitted to the means of which exponent is 0.916 (see text).

\section{Perceived Distance}

The mean perceived distances averaged over three trials for each participant and for each viewing distance were the basic unit for further analyses. A one-way (8 Viewing Distances) repeated measure ANOVA was performed. The results showed that the main effect of the viewing distance was significant, $F(7,126)=116.961, p<.001$. The significant main effect is illustrated in Figure 2, in which the mean perceived distance averaged over 19 observers is plotted as a function of the viewing distance. The exponent of power function fitted to the mean perceived distance was 0.916 , and coefficient of determination was 0.996 .

The value of the power exponent obtained in this study was comparable to the results of previous studies; consequently, the present perceived distance data seem to be appropriate. Previous studies (e.g., Da Silva, 1985; Higashiyama, 1993) showed that the mean exponent of the power function fitted to the mean perceived distance obtained in the full-cue condition was between 0.85 and 0.97 . The exponent of 0.916 obtained in the present study is within this range.

The perceived distances were veridical at near viewing distances under eight meters and relatively underestimated at far viewing distances over eight meters. The results of the 95\% confidence intervals calculated from the obtained means and standard deviations for viewing distances of $8.6 \mathrm{~m}$ were 5.70-8.04 m; of $11.5 \mathrm{~m}, 7.46-10.84 \mathrm{~m}$; of $13.8 \mathrm{~m}, 9.18-13.11$ $\mathrm{m}$; and of $18.3 \mathrm{~m}, 11.84-16.35 \mathrm{~m}$. None of the four physical distances $8.6 \mathrm{~m}, 11.5 \mathrm{~m}, 13.8 \mathrm{~m}$, and $18.3 \mathrm{~m}$ were contained in any of the $95 \%$ confidence intervals. These values show that the perceived distance was underestimated under these viewing distance conditions. This is illustrated in Figure 2.

\section{Relationships between Perceived Size and Distance}

Figure 3 shows the perceived size plotted as a function of the perceived distance, separately for the afterimage and real object. The mean slopes of the linear regression lines calculated for each observer and averaged over 19 observers were $0.175(S D=0.0073)$ for the afterimage, and 0.196 (SD $=0.0054$ ) for the real object. The results of a $t$ test showed that there was no significant difference between the two mean slopes, $t(18)=1.683$, n.s.

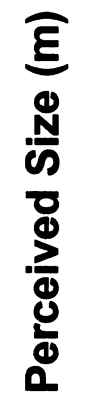

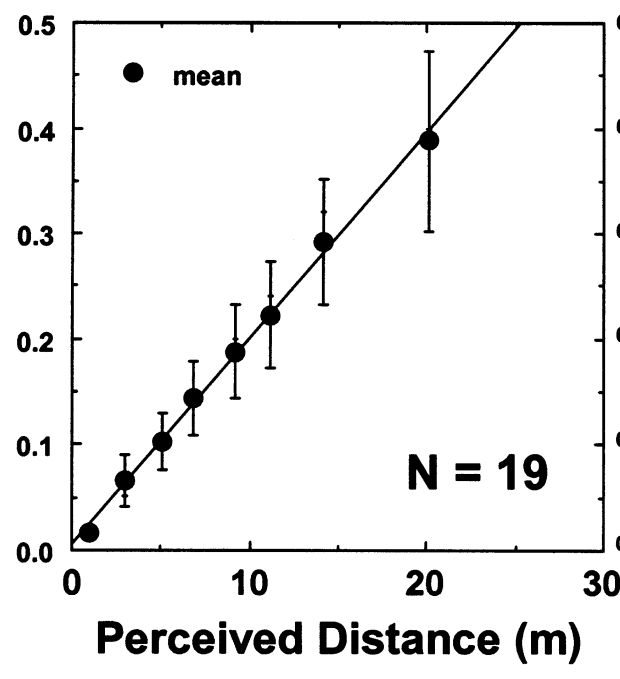

(a)

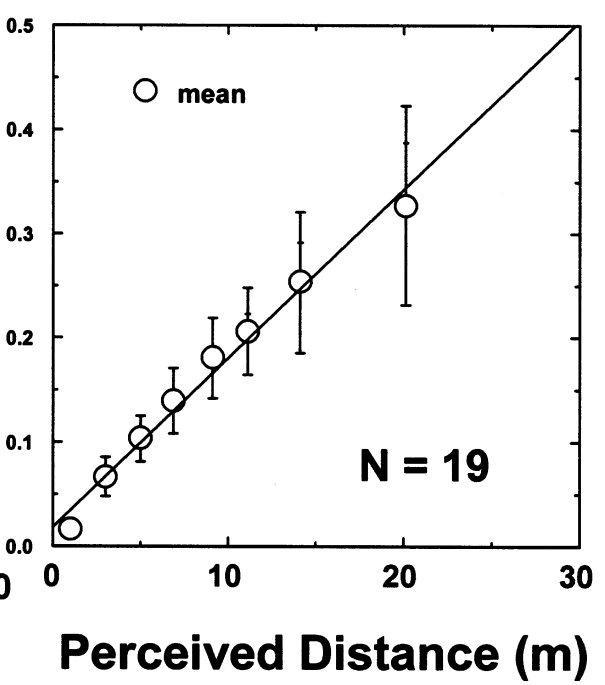

(b)

Figure 3. The perceived size plotted as a function of the perceived distance. (a) real object and (b) afterimage. The thin vertical lines indicate the standard deviations. The linear regression lines are shown in the figures. 


\section{Discussion}

The present study provides evidence to show that Emmert's law and the size-distance invariance hypothesis are formally equivalent, provided that Emmert's law means that the perceived size of an afterimage is proportional to the perceived distance of the projected surface. Several researchers (e.g., Higashiyama, 1993; Howard \& Rogers, 2002) have argued that the law and the hypothesis are formally equivalent, but until the present work, no study has been conducted empirically to test this argument. Our findings showed definitively that the perceived size is proportional to the perceived distance equally for both afterimage and real object with the same proximal sizes, at least in relatively small viewing distances, when examined in the same experimental environment.

With viewing distances of over approximately $13 \mathrm{~m}$, there were slight differences in perceived size between the afterimage and real object. The exact reason for this is not clear from the results of the present study, but we think that size perception of real objects is veridical in almost all viewing distance conditions; this means that size constancy is held based on many cues to depth as well as cues to distance, as shown in Figure 1, notwithstanding the fact that the perceived distance is not always veridical under long viewing distance conditions. On the other hand, size perception of the afterimage does not always correspond to the geometric predictions from Equation 2 in all viewing distance conditions. We think this is because the afterimage is not a real object, but a "virtual" object. This could be one of reasons why there is a difference in the perceived size between the afterimage and the real object under the longdistance viewing conditions used in the present study.
Distance scaling is a general characteristic of the visual system to recover veridically physical attributes of the outer world, such as depth, motion, and size. The present study showed that the perceived sizes of the afterimage and the real object can be scaled, or calibrated, by using perceived distance information.

\section{References}

Da Silva, J.A. (1985). Scales for perceived egocentric distance in a large open field: Comparison of three psychophysical methods. American Journal of Psychology, 98, 119-144.

Higashiyama, A. (1994). Space perception. In T. Ohyama, S. Imai, \& T. Wake (Eds.), Handbook of sensory and perceptive psychology. Tokyo: Seishin Shobou.

Howard, I.P., \& Rogers, B.J. (2002). Seeing in depth. Vol. 2, Depth perception. Toronto: I.P. Porteous.

Inoue, E. (1972). Perceived size of an afterimage in the visual space. Proceedings of $36^{\text {th }}$ Annual Meetings of Japanese Psychological Association (p. 114).

Nakamizo, S., \& Imamura, M. (2004). Verification of EmmertПs law in actual and virtual environments. Journal of Physiological Anthropology and Applied Human Science, 23, 325-329.

Weintraub, D.J., \& Gardner, G.T. (1970). EmmertПs law: Size constancy vs. optical geometry. American Journal of Psychology, 83, 40-54.

Young, F.A. (1948). The projection of after-image and EmmertПs law. Journal of General Psychology, 39, 161-166.

Received December 15, 2005

Review received May 2, 2006

Accepted May 4, 2006 